\title{
DEMOGRAPHIC FAULTLINES AND CREATIVITY IN DIVERSE GROUPS
}

\section{LISA H. NISHII}

JACK A. GONCALO

The ILR School, Cornell University

Contact:

Lisa Nishii - 1hn5@cornell.edu

Jack Goncalo - jaq97@cornell.edu 


\begin{abstract}
Despite the oft made argument that demographic diversity should enhance creativity, little is known about this relationship. We propose that group diversity, measured in terms of demographic faultlines, affects creativity through its effects on group members' felt psychological safety to express their diverse ideas and the quality of information sharing that takes place across subgroup boundaries. Further, we propose that the relationship between faultlines and creativity will be moderated by task interdependence and equality of subgroup sizes. Finally, we provide suggestions for how organizations can establish norms for selfverification and use accountability techniques to enhance creativity in diverse groups.
\end{abstract}




\section{Introduction}

Many scholars have argued that increased demographic diversity should benefit organizations because more diverse groups should be better able to engage in creative and innovative decision making (Cox, 1993). Indeed, this line of thinking has spawned almost two decades of research in search of the elusive bottom-line benefits associated with a demographically diverse workforce. Curiously, however, despite the fact that the value in diversity hypothesis focused on creative or innovative solutions as the expected beneficial outcome of diversity (Cox, Lobel, \& McLeod, 1991; McLeod, Lobel, \& Cox, 1996), most research has focused on outcomes other than creativity and innovation (see Milliken \& Martins, 1996; Williams \& O'Reilly, 1998 for reviews). The paucity of research on creativity in diverse groups is not only perplexing (see Gibson \& Vermeulen, 2003; McLeod, et al., 1996 for examples of exceptions), it is also problematic, given the increasing need for organizations to innovate in order to compete in the global marketplace (Subramaniam \& Youndt, 2005). It leaves unanswered the question of whether, and under what conditions, diversity is good for creativity.

On the one hand, diverse groups have access to different backgrounds, perspectives, and opinions that can stimulate and enhance creativity (Amabile, 1996; De Dreu \& West, 2001); thus they should be in an advantageous position when it comes to innovation. On the other hand, based on arguments associated with social categorization theory, it is easy to see how increased diversity might be associated with greater social disintegration, and as a result, reduced abilities of groups to engage effectively in creative processes (Ancona \& Caldwell, 1992; Chatman, Polzer, Barsade, \& Neale, 1998). These conflicting arguments suggest that simply stating that increased diversity will lead to greater creativity is overly simplistic. Instead, certain group 
conditions must be in place in order to facilitate the use of diverse perspectives toward innovative solutions. In particular, not only do diverse perspectives need to be present, group members must feel willing to communicate and be open to the ideas of different others. Without conditions that facilitate the sharing and communication of ideas, the diverse perspectives present in the group will not have a chance to surface and stimulate creative decision making.

In this paper, we argue that examining diversity in terms of faultlines rather than overall heterogeneity within a group may help elucidate the complex relationship between diversity and creativity for two reasons. First, the strength of group faultlines, or the extent to which hypothetical dividing lines split a group into subgroups based on the alignment of one or more demographic attributes (Lau \& Murninghan, 1998), plays a large role in determining the social processes that unfold within a group, thereby influencing the extent to which a diverse group is able to capitalize on its diversity of perspectives. As we describe below, groups with strong faultlines tend to be more polarized, and as a result suffer from group conflict, lack of communication, and behavioral disintegration (Lau \& Murnighan, 2005; Li \& Hambrick, 2005). Second, because diversity is thought to be beneficial when the diverse opinions, experiences, and values associated with demographic diversity interact to create novel solutions, the faultlines approach is more appropriate than traditional measures of diversity since it analyzes the effects of demographic characteristics in combination rather than in isolation of each other.

\section{Demographic faultlines}

Demographic faultlines in groups range from weak to strong. When groups first form, group members are thought to use salient individual attributes (e.g., demographic characteristics) to categorize group members into subgroups. The more demographic attributes are correlated, the fewer the number of subgroups that can be formed and the greater the homogeneity within 
subgroups (Lau \& Murninghan, 1998). In contrast, faultlines are weakest in groups where demographic attributes are not aligned and many cross-cutting subgroups can be formed, thereby weakening the possibility of strong subgroup-identifications among group members and blurring the lines that demarcate ingroups from outgroups. In terms of probability, the greater the number of factors represented in a group, the less likely they are to perfectly align so as to create strong faultlines (Shaw, 2004). Similarly, the greater the variance on some factor, the more it contributes toward a weaker faultline within the group since it becomes less likely for the factor to contribute to alignment across workers. For example, if all 4 people in a group differ on race, then race will not strengthen a faultline, it will only weaken it; however, if two of the people are Asian and the other two are Caucasian, then race is more likely to contribute to a strong faultline within the group.

Any attributes on which individuals differ can conceivably contribute to group faultlines: surface-level demographic attributes such as race, gender, and age, as well as deeper-level attributes such as personality, attitudes, educational background, hobbies, and the like. The attributes that actually contribute to group faultlines, however, are those that are activated and made salient within any particular task or social context (Bezrukova \& Jehn, 2003). Although no work has examined this, we might even expect the attributes that define faultlines to shift within a group over time. Work by Harrison and colleagues (Harrison, Price, \& Bell, 1998), for example, suggests that faultlines might initially be defined by the alignment of surface-level demographic attributes, but over time, may come to be defined more by deeper-level characteristics. Thus, a group that is initially highly polarized based on perfect alignment of race and gender within the group (e.g., all men are Asian while all women are Caucasian) may, over time, experience a weakening of the faultline once group members discover that their similarities 
and differences in personality, political beliefs, and academic training cut across that initial faultline. The degree to which this shift occurs may vary across groups: if strong coalitions form within a group, then members of the coalitions often maintain separate subgroup identities in an effort to preserve their unique subgroup cultures (Deutsch, 1973; Eisenhardt \& Bougeois, 1988). If coalition members continue to cooperate with each other but are not motivated to also cooperate and communicate with noncoalition members, then the resulting inter-subgroup relationship conflict in the group may prevent the discovery of deeper-level similarities across coalition lines, thereby making it unlikely for faultlines to shift.

The important thing is that the differences be perceived as real and relevant by group members, because it is the perception that there are differences among group members that leads to the social categorization processes that increase inter-subgroup bias and friction. If only a subset of the attributes on which group members actually differ are seen to be important or relevant, then those factors will have stronger dividing power on the group. Even though past research has suggested that surface-level, non-work factors evoke stronger negative stereotypes than non-visible or deep-level characteristics (Milliken \& Martins, 1996; Pelled, Eisenhardt, \& Xin, 1999) and therefore might have stronger "dividing" power than deeper-level factors, this may not necessarily be the case if these surface-level factors are considered to be irrelevant for the nature of the group or task at hand.

\section{Outcomes associated with group faultlines}

Consistent with past research on relational demography, research on demographic faultlines has also focused primarily on performance outcomes other than creativity (e.g., Li \& Hambrick, 2005; Thatcher, Jehn, \& Zanutto, 2003). Many scholars have argued (e.g., Lau \& Murnighan, 1998; Sawyer, Houlette, \& Yeagley, 2006), and some have found (Li \& Hambrick, 
2005; Sawyer et al., 2006; Thatcher et al., 2003), that strong faultlines tend to be bad for performance, since groups with strong fautlines are divided into subgroups which often compete for resources and suffer from social disintegration (Li \& Hambrick, 2005). Specifically, strong faultlines are associated with higher levels of conflict, lower group cohesion, and weaker communication across subgroups (Lau \& Murnighan, 1998; Sawyer, Houlette, \& Yeagley, 2006) than is the case in groups with weak faultlines.

The relative lack of a focus on outcomes related to creativity may be due at least in part to arguments made by Lau and Murnighan (1998) in their pioneering article on faultlines. They argued that faultlines "are likely to have much less impact on creativity" than demographic diversity as traditionally conceptualized (1998: p. 331). We propose, however, that under certain conditions demographic faultlines may actually mitigate some of the most serious barriers to creativity in groups. In other words, in contrast with the negative relationship that has been found between faultlines and other measures of performance, and also in contrast to Lau and Murnighan's original arguments, we argue that faultlines are good for creativity under certain conditions.

Next, we begin with a brief discussion of creativity and set the stage for our propositions regarding the relationship between demographic faultlines and creativity in groups. We differentiate between two important stages of the creativity process - idea generation and idea selection - and offer propositions for each of these stages. We also extend ideas about strategies that organizations and their leaders can implement to overcome difficulties experienced by certain types of groups during idea generation and selection.

Creativity 
A creative idea is most often defined as one that is both novel and useful (Amabile, 1983). It is novel because it diverges from existing solutions and useful in that it presents a potentially viable solution to a problem. In organizations such ideas may relate to a wide variety of domains such as organizational products, practices, services or procedures (Shalley \& Gilson, 2004). Creativity can be distinguished from innovation. Whereas creativity is focused on the development and generation of new and useful ideas, innovation refers to the process through which they are successfully implemented at the organizational level (Amabile, 1996).

The early research on creativity was conducted primarily at the individual level; especially on the traits that distinguish highly creative individuals from their peers (Helson, 1996). This research has shown that highly creative people tend to score high on traits such as openness to experience and tolerance of ambiguity (Barron \& Harrington, 1981). Such traits allow creative people to acquire a vast and diverse repertoire of information that can be combined in a novel way (Kasof, 1997). Creative people are also described as being exceptionally independent and self-confident, allowing them to persistently support their own ideas even in the face of criticism (Helson, 1996).

The large body of research on individual personality traits fits with the widespread belief that creative insights are most likely to emerge from the mind of a lone genius working in isolation (Perry-Smith \& Shalley, 2003). Recently, however, there has been a major shift in the way work is conducted such that organizations are becoming increasingly "team" based and employees are spending more time working as a member of a group (Ilgen, Major, Hollenbeck, \& Sego, 1993; McGrath, 1997; Ilgen, 1999; Locke et al., 2001). In line with this shift, most organizations rely heavily on brainstorming groups as a source of creative ideas (Paulus \& Yang, 2000) and most people who participate in brainstorming sessions believe that they are much 
more creative than they would have been if they generated ideas alone (Stroebe, Diehl, \& Abakoumkin, 1992).

Yet, surprisingly, numerous studies have shown that face-to-face groups generate fewer ideas than nominal groups in which individuals first generate ideas alone and then combine their non-redundant ideas to form a common list (McGrath, 1984). Groups can potentially be creative by building upon, combining and improving each member's ideas (Osborn, 1953). But they often fail to reach their potential because group interactions are often inefficient or otherwise produce obstacles to effective brainstorming (Milliken, Bartel, \& Kurtzberg, 2003). One of the most important such obstacles is evaluation apprehension (Diehl \& Stroebe, 1987). In group contexts, individuals have been found to offer fewer ideas as a result of feelings of inhibition and reluctance borne out of a fear of being negatively evaluated by group members (Camacho \& Paulus, 1995). Thus, even though groups have the potential to be more creative than individuals, the group context itself can be a formidable barrier to creativity.

Creativity at the group level is typically measured by the sheer number of ideas a group is able to generate in a fixed amount of time (Brophy, 1998). Those ideas are also typically rated by having outside judges rate the novelty and usefulness of each idea (Diehl \& Stroebe, 1987). Almost all of the existing research has focused on idea generation and consequently we know very little about how groups select ideas for implementation (Rietzschel, Nijstad, \& Stroebe, 2006). This is a serious limitation because brainstorming groups are often used in organizational settings (Paulus \& Yang, 2000) and the only way to realize the practical benefits of brainstorming is to actually select an idea that can eventually be turned into a viable product (Amabile, 1996). Although most studies show a strong positive correlation between the sheer number of ideas generated and the number of creative ideas generated, the mere availability of 
creative ideas does not guarantee their selection (Rietzschel et al., 2006). In this paper, we focus on both idea generation and idea selection: whether or not diverse groups are creative depends both on whether group members are willing to voice their diverse ideas, and also on whether those ideas are considered by the rest of the group when selecting the best ideas for implementation.

\section{Faultlines and creativity in diverse groups}

Many scholars have argued that creativity can be stimulated by increasing the demographic diversity of the group (Williams \& O'Reilly, 1998). Research on groups has shown that creativity is stimulated by a variety of opinions (Nemeth, 1986) and knowledge (Jehn, Northcraft, \& Neale, 1999), provided that such diverse perspectives are actually shared with the rest of the group (Stasser \& Stewart, 1992). The sharing of diverse perspectives gives rise to task conflict (Jehn, 1995) which in turn leads people to think more divergently (Gruenfeld, 1995). When thinking about the sharing of diverse perspectives in groups, however, it is critical that one first consider the intragroup dynamics that are likely to influence information sharing and communication within the group. Diversity research which focuses on one aspect of diversity at a time, or which focuses on the total amount of diversity without considering the pattern or structure of that diversity, may fail to capture the complexity of intragroup interactions. Depending on the group context and the ways in which the diversity characteristics present in a group interact, any particular set of diversity characteristics may be more or less salient (Lau \& Murnighan, 1998; Sawyer et al., 2006).

A group with strong faultlines is characterized by the formation of homogeneous subgroups within which members' demographic attributes are closely aligned. Identification with such clearly defined subgroups is thought to be strong, thereby contributing to ingroup- 
outgroup dynamics. Although groups with strong faultlines might not easily or frequently communicate across subgroup boundaries (Lau \& Murnighan, 1998), strong faultlines might actually provide pockets of social support within subgroups that can facilitate idea sharing. When individuals associate and identify with other similar individuals, they can count on receiving support from them. As a result, they feel that it is psychologically safer to vocalize their ideas, as the "fear of embarrassment" (Gibson \& Vermeulen, 2003), or apprehension evaluation, is reduced (Asch, 1952; Crott \& Werner, 1994; Edmondson, 1999). Given that research has found that apprehension evaluation is a formidable obstacle to individuals' contribution to idea generation processes, group dynamics that can help ameliorate such evaluation apprehension increase the free expression of ideas. To the extent that individuals will feel secure at the thought of receiving support from similar others, they should be more willing to share their ideas with the other members of their subgroup.

Yet while the sheer number of ideas that people feel comfortable sharing might increase, the range of ideas expressed may be highly constrained within the subgroup environment. Recent research suggests that in-group members expect to agree with one another (Phillips, 2003) and when these expectations are violated, critical or unique information may be discounted (Phillips, Mannix, Neale \& Gruenfeld, 2004). In other words, members of a homogeneous subgroup may feel pressure to conform to the opinions of other in-group members, which may in turn cause the group to generate ideas that are highly similar to each other. Any pressure to conform to or mimic the ideas of other in-group members may reduce homogenous subgroup members' ability to think creatively (Nemeth \& Staw, 1989). Subgroup members who feel comfortable with each other but do not communicate with the larger group may eventually 
experience groupthink (Janis, 1971) and begin to overestimate the uniqueness and creativity of their own ideas (Paulus, Dzindolet, Poletes, Camacho, 1993).

In contrast, groups with weak faultlines might encounter the greatest difficulty with idea generation because people's identities do not converge and therefore individuals cannot take advantage of the psychological safety afforded by cohort membership (cf. Gibson \& Vermeulen, 2003). Indeed, research on heterogeneous groups (which tend to be the ones with weak faultlines since the possibility for the alignment of numerous attributes decreases as the number of group member attributes increases; Lau \& Murnighan, 1998) suggests that greater diversity is associated with dysfunctional conflict and turnover, as well as detriments in cohesion, social integration, communication and information sharing, and therefore group performance (Polzer Milton, \& Swann, 2002; Williams \& O’Reilly, 1998). Thus, even though groups with weak faultlines tend to be the ones with greatest diversity, and therefore should in theory have a potentially greater distribution of information available to incorporate in idea generation, they are least likely to be able to capitalize on that information.

In sum, creativity should be constrained at the extremes of faultline strength. On the one hand, strong faultlines may afford the greatest social support and solidarity from other ingroup (i.e., subgroup) members, but the ideas produced may be plentiful but also highly similar to each other. On the other hand, weak faultlines may provide the greatest raw material in terms of a wide range of information on which to draw upon, such information might not be expressed in highly diverse groups. Logically, the most creativity should occur when people benefit from support via in-group membership but also when they are sufficiently open to discussing their ideas with people who are different from them; precisely the conditions that might be present in a group with moderate faultlines. Such groups not only benefit from subgroup-identification 
which, as we have argued, provides the social support that individuals may need to voice their different viewpoints to the team, they also benefit from cross-cutting ties that link members of one subgroup to members of another. Thus, we can expect that in groups with moderate faultlines, there will be greater subgroup coordination and communication, thereby facilitating greater overall sharing of diverse ideas within the group. In other words, the dual advantages of in-group support combined with inter-subgroup communication may stimulate the free exchange of novel ideas. Thus, we propose:

Proposition 1a: The sheer number of ideas generated by groups with strong faultlines will be greater than the number of ideas generated by groups with moderate or weak faultlines.

Proposition 1b: The novelty of ideas generated by groups with moderate faultlines will be greater than the novelty of ideas generated by groups with strong or weak faultlines. An important consideration when predicting the relationship between faultlines and idea generation, however, is the level of task interdependence. Task interdependence refers to the extent to which group members rely on, and need to interact with, each other to perform their tasks effectively (Kiggundu, 1981; Wageman, 1995). Task interdependence is positively associated with a need for cooperation, communication, and coordination (Saavedra, Earley, \& Van Dyne, 1993), and tends to result in more mutual helping and information sharing than noninterdependent group tasks (Wageman, 1995). Thus, as the outcomes for one individual are influenced by the actions of others, information exchange among group members is expected to increase, thereby influencing the extent to which diverse ideas are likely to be shared within groups, and in particular across subgroups. One of the advantages of brainstorming as a group is that people can potentially build upon, combine, and improve each other's ideas to generate ideas 
that are more novel than any one person could have generated alone (Diehl \& Stroebe, 1987). Recently, Nijstad and Stroebe (2006) proposed a cognitive model of idea generation in groups in which the process of sharing and paying attention to one another's ideas might lead to a mutually stimulating effect that results in a wider range of ideas. Therefore, creativity is often facilitated when people are encouraged to collaborate with one another (Audia \& Goncalo, 2007).

In proposition 1, we predicted that groups with strong faultlines may be constrained in the idea generation stage because reduced communication and coordination would block the cross-fertilization of ideas across sub-group boundaries. We expect, however, that when strong faultline groups are characterized by high task interdependence, communication and coordination among group members, including among members in different subgroups, will improve, thereby leading to better overall quality and quantity of idea generation within the group. In fact, once the subgroup communication barriers are ameliorated by the need for coordination, we expect that groups with strong faultlines will be even more creative than groups with moderate faultlines. This is because people tend to be more accepting of different ideas and information when it comes from people who are different rather than similar to oneself (Phillips et al., 2004), and in groups with strong faultlines, it is easy to see who is similar and who is different, since they are characterized by homogeneous subgroups. Thus, provided individuals are motivated to cooperate and communicate with members of the other subgroups as they are when they are highly interdependent, the potential for creativity should be highest in strong faultline groups.

Our expectation is further supported by work that suggests that creativity at the group level requires that group members feel psychologically safe to express one's ideas (Diehl \& Stroebe, 1987; Edmondson, 1999) vis-à-vis the support of subgroup members, and also to stand 
out from the group to suggest novel ideas (Goncalo \& Staw, 2006; Beersma \& De Dreu, 2005). Brewer's (1991) theory of optimal distinctiveness suggests that individuals' sense of security, self-worth, and self-identity are maximized when they simultaneously satisfy the need for deindividuation through membership with distinct ingroups, and their need for distinctiveness by being able to make clear intergroup comparisons against definable and relevant outgroups. These circumstances are most consistently met in groups with strong faultlines, in which there are few, homogeneous subgroups. The willingness to express ideas should be increased via the sense of belongingness derived from subgroup membership but the ideas expressed should also be more creative because peoples' distinct attributes are made salient when interacting with the members of another subgroup. De-individuation and distinctiveness are not optimized in groups with moderate faultlines, in comparison, because cross-cutting group memberships blur the bases of subgroup membership, thereby attenuating one's ability for de-individuation and distinctiveness.

We previously suggested that groups with moderate faultlines would ordinarily outperform groups with strong faultlines because cross-cutting group memberships would facilitate idea sharing across subgroups. However, we expect task interdependence to have less of an effect on groups with moderate faultlines, since inter-subgroup communication channels are already presumed to be open, by virtue of cross-cutting memberships in subgroups. Similarly, we expect task interdependence to have little effect on the ability of groups with weak faultlines to generate ideas, as task interdependence alone is unlikely to provide psychological guarantee that an individual can count on the support of other group members when enacting their suggestions. Thus, we propose: 
Proposition 2: The level of task interdependence that characterizes a group will moderate the relationship between group faultline strength and group creativity. Specifically, high task interdependence will cause groups with strong faultlines to generate more creative ideas than groups with moderate faultlines and groups with weak faultlines will generate the fewest novel ideas.

As we mentioned previously, almost all of the existing research on creativity has focused on idea generation and consequently we know very little about how groups select ideas for implementation (Rietzschel et al., 2006). Almost no research exists to explain the process that groups use to select creative ideas or how the process can be improved. Here we extend our analysis by considering the relationship between faultlines and creative idea selection by groups.

Although strong faultlines might be advantageous in terms of providing people with the support and perceived psychological safety (Edmondson, 1999) that is necessary to encourage idea generation, strong faultlines might create problems when groups need to select a single idea for implementation. Specifically, we argue that strong faultlines might create subgroups that may then polarize (Mosovici \& Zavalloni, 1969) and lead the members of each subgroup to favor ideas that were suggested by members of their own group. Early research related to this idea showed that when groups engage in discussions about some idea, they tend toward riskier preferences than individuals making judgments alone (Stoner, 1961). Subsequent research designed to clarify and expand upon these ideas revealed that it is not so much that groups tend to become more risk-taking as a result of discussions, but that group discussions tend to make individual attitudes more extreme (Moscovici \& Zavalloni, 1969). This happens because public discussion produces commitment to a particular point of view (Moscovici \& Zavalloni, 1969), and because discussing the reasons behind shared beliefs strengthens people's conviction in 
those beliefs (Myers \& Lamm, 1976) by providing additional reasons for maintaining their beliefs (Burnstein \& Vinokur 1973). Indeed, within groups, each idea that is suggested provides evidence in favor of the validity of an entire category of similar ideas (Burnstein \& Vinokur, 1973).

This process of polarization is particularly problematic for groups with strong faultlines where individuals are likely to first discuss their ideas among subgroup peers. Such discussions are likely to make within-subgroup ideas more extreme and potentially lead people to build upon ideas suggested by members of their own subgroup while disregarding the ideas suggested by members of the other subgroup. By supporting each other's ideas, they are implicitly committing themselves to the validity of those ideas and to defending those ideas at the implementation stage. The net result of this polarization process is that each subgroup will be subject to group serving biases in their evaluation of ideas (Taylor \& Doria, 1981), leading to deadlocks (Lau \& Murnighan, 1998) and preventing a convergence of opinions on which idea the group should pursue (Abrams et al., 1990; Gibson \& Vermuelen, 2003). It is important to note that consistent with arguments that we made in relation to Proposition 2, we expect these problems to be especially acute in groups that are working on tasks that are not highly interdependent. Therefore, we predict the following:

Proposition 3: Inter-subgroup conflict in groups with strong faultlines will prevent them from selecting their most creative idea for implementation, as subgroup members will be committed to defending the ideas that emerge from their subgroups without fully considering ideas generated by competing subgroups.

Although there is a great deal of theoretical evidence that strong faultlines will lead to subgroup conflicts - and that such conflicts may prevent groups from selecting their most 
creative ideas - the empirical research on demographic faultlines has often failed to verify the purported link between faultlines and conflict in groups. For instance, Thatcher and her coauthors (2003) found that groups with strong faultlines actually experienced less conflict than groups with weak faultlines. It may be that the relationship between faultlines and group conflict is actually more complex than originally theorized and that characteristics of the subgroups themselves, such the equality of the size of subgroups, may play an important role in influencing the level of conflict across faultline boundaries.

Competition theories (Blalock, 1967) suggest that conflict arises because people often assume that there is a finite set of resources. When one subgroup is small relative to the other, the potential for conflict is lessened because the larger subgroup is less likely to perceive the smaller subgroup as a threat to their power, status or available resources, as compared to when subgroups are of comparable size and therefore competition for resources is magnified (Mannix $\&$ Neale, 2005). This is illustrated in research by Tolbert, Andrews and Simons (1995), who found in a study of 50 sociology departments, that as the number of women increased, fewer women were hired. They concluded that as the number of women in the group increased and approached the number of men in the group, the environment for women became increasingly negative. This research suggests that groups with strong faultlines that are composed of subgroups of unequal size will have fewer problems agreeing on and selecting a creative idea than groups with strong faultlines that are composed of subgroups of equal size. Subgroups of equal size are more likely to perceive a threat to their dominance and these perceived threats may lead to increased conflict and competition which may play out as subgroups compete to have their idea selected for implementation. 
There is no reason to believe, however, that unequally sized subgroups will experience zero conflict. It is simply that when there is a disparity in subgroup size, it may be more possible to harness subgroup conflict to improve the quality of the group's decision making process in ways that are less likely for equally sized subgroups. Although it is of course possible that the larger subgroup may ultimately prevail by forcing the rest of the group to endorse one of their own ideas, the presence of a relatively unthreatening, smaller subgroup that actively promotes their ideas may lead the group to consider more ideas overall (Nemeth, 1986). And when a greater range of ideas emerging from both sides of the faultline are considered prior to selection, the process will be less biased (Nemeth \& Rogers, 1996) and therefore potentially better. It is also possible that subgroups may eventually compromise, not by selecting only one idea, but by creatively combining several ideas to reach a more multi-faceted and novel solution (Goncalo \& Staw, 2006). In sum, subgroups of unequal size may provide enough conflict to improve the quality of the final decision without leading to the potentially intractable conflict that may emerge between two equally powerful coalitions. Therefore, we predict the following:

Proposition 4: The negative relationship between faultine strength and creative idea selection will be moderated by relative sub-group size such that strong faultine groups with subgroups of unequal size will experience less conflict and will select more creative ideas than will strong faultline groups with subgroups of equal size.

Proposed strategies for overcoming low levels of creativity In past research on faultlines, numerous scholars have offered practical solutions to overcoming the problematic outcomes associated with varying levels of faultline strength. Among these, one of the most commonly proposed strategies has been for organizations to take great care in designing their groups, so as not to create groups with strong faultlines that would 
be susceptible to negative inter-subgroup dynamics (e.g., Molleman, 2005; Sawyer et al., 2006). This proposed strategy may be difficult to implement successfully in organizational contexts. First, it is unrealistic (cf. Thatcher et al., 2003) to expect managers to have the luxury of picking and choosing the members that will constitute groups based on demographic characteristics. Instead, individuals enter work groups as they are hired, promoted, or transferred into those groups, without regard for whether their particular set of demographic attributes represents a "good fit" with those already represented within the group. Furthermore, even if a manager were able to hand-select members based on their observable demographic characteristics, the attributes that determine faultlines are thought to be contextually defined (i.e., according to the demands of the task; Crisp \& Hewstone, 2001; Lau \& Murnighan, 1998) and therefore faultlines other than those that were expected could emerge. In addition, faultlines may emerge on the basis of unobservable, deeper-level characteristics rather than - or in addition to - observable surfacelevel characteristics (Moelleman, 2005), thereby reducing a manager's likelihood of being able to predict optimal group design.

In this section we offer organizational interventions for increasing creativity in diverse groups that can be implemented with pre-existing groups. In doing so, we focus specifically on the group types that we have identified as suffering from problems at the idea generation and idea selection stages. With regard to the former, we predicted that groups with weak faultlines would perform poorly at idea generation, and thus we tailor our intervention strategy to this case. With regard to the latter, we proposed that groups with strong faultlines would suffer from intersubgroup conflict and therefore perform poorly at idea selection, and thus we offer an intervention strategy focused on groups with strong faultlines.

Proposed strategy for improving idea generation in groups with weak faultines 
As we highlighted previously, the main obstacle to effective idea generation in groups with weak faultlines is that without the psychological safety afforded by subgroup peers, group members may feel reluctant to openly share their ideas, particularly if they perceive their ideas to be different. Drawing from self-verification theory (Polzer2002; Swann, Kwan, Polzer, \& Milton, 2003; Swann, Milton, \& Polzer, 2000), we expect that when groups adopt norms about self-disclosure early in the life of the group, such that group members are encouraged and expected to actively externalize their self-views rather than deemphasize or shy away from expressing them, group members will feel more comfortable expressing their unique ideas, even in the perceived absence of support from subgroup peers. When people engage in selfdisclosure, they can start to feel known and understood by group members, thereby helping them to feel connected to the group, and safe about behaving authentically and expressing their unique ideas (Swann et al., 2003). As a consequence, the number of divergent ideas expressed should increase and creative idea generation should flourish, since the presumed obstacle to idea generation will be removed. In support of this notion, Swann and his colleagues (2000) found that the more targets engaged in self-disclosure and brought other group members to see them congruently - as they see themselves - the more connected they felt to group members and the better the group's creative task performance. They explained that once group members verify each other's views, they not only begin to understand each other, but also come to expect vast differences amongst themselves, thereby making it less likely that behaviors that might otherwise disrupt group interactions, such as relational conflict among dissimilar individuals, will actually do so (Polzer et al., 2002).

This idea, that interpersonal congruence through self-verification would enhance the performance of diverse groups, was echoed by the work of Ely and Thomas (2001), who found 
that group members who perceive that diversity is a resource for learning and adaptive change feel more comfortable expressing who they are at work, including what makes them unique. Such a focus on the value of diversity for the group is thought to facilitate mutual respect and minimize potential threats to the distinctiveness of self-identities (Van Knippenberg, et al., 2004). Indeed, the view that creating group norms around openly sharing and processing diverse viewpoints can improve the quality of decision making within diverse groups has been echoed by others (e.g., Lau \& Murnighan, 1998; Phillips, Northcraft, \& Neale, 2006; Van Ginkel \& Van Knippenberg, 2003). Postmes and his colleagues (2001), for example, found that norms of consensus, which focus on reaching agreement and discovering commonalities, undermined the sharing of unique information in groups, whereas norms for critical thought facilitated information exchange and improved the quality of group decisions. Interestingly, Earley \& Mosakowski (2000) found that the establishment of group norms alone is very important in diverse groups, since the very perception that group members share normative expectations with other group members can facilitate the type of positive affect and trust required to fuel group efficacy and performance.

Group leaders can play an influential role in facilitating self-verification and interpersonal congruence among group members by acting as the "trigger" (Polzer et al., 2002; p.317) that jump-starts the self-disclosure process among group members. Such triggers are thought to explain why some diverse groups achieve higher levels of interpersonal congruence than others. We expect that once self-verification processes are triggered in groups with weak faultlines and individuals feel comfortable expressing their divergent ideas, they will be in a position to generate as many creative ideas as groups with strong faultlines (in which we 
hypothesized that individuals will feel psychologically safe to express divergent ideas as a function of subgroup support). Accordingly, we propose:

Proposition 5: Groups with weak faultlines that establish norms for self-verification, will generate more ideas than weak faultline groups that do not establish norms for selfverification. In fact, groups with weak faultlines that implement this intervention should generate as many creative ideas as groups with strong faultlines.

Accountability as a strategy for improving idea selection in groups with strong faultlines

As with idea generation, given the potential problems that may arise in groups with strong faultlines at the idea selection stage, it would be useful to develop managerial strategies that might help groups with strong faultlines to avoid these negative outcomes. One possibility that seems especially promising is to hold each group accountable for the idea they select. Accountability refers to implicit or explicit expectations that an individual or group may be called upon to justify their beliefs, feelings and actions to others (Tetlock, 1992). Holding groups accountable is realistic, since in organizations, it is unlikely that groups will be selecting creative ideas in a social vacuum (Lerner \& Tetlock, 1999). At some point, they will probably have to justify their selection to some external evaluator. In order to pursue an idea through the implementation stage, a group must convince others that their idea is worthwhile and seek funding and approval from upper management (Chell, Haworth, \& Brearley, 1991). This process of seeking approval for a particular idea may present an opportunity to reduce the biases and inter-subgroup conflicts that may arise in strong faultine groups. The issue, however, is in what manner groups with strong faultlines should be held accountable: to whom, and for what?

One way of holding people accountable for their ideas is to provide incentives in the form of rewards or recognition for creative ideas that may potentially result in profitable products 
(Amabile, 1996). For instance, Art Fry, the scientist at 3M who is credited with the invention of the Post-It Note, continues to be recognized at 3M for creating a product that spawned several different product lines and generated millions of dollars over the last two decades (Christensen, 1997). However, rewarding creativity can backfire at the individual level because people who are extrinsically motivated are generally less creative (Amabile, 1983), and at the group level, such rewards may backfire in groups with strong faultlines by inciting destructive conflict over which subgroup gets to claim credit for a particular idea. The potential problems that may result from rewarding creativity suggests that the use of accountability as a mechanism for managing creativity in strong faultline groups can only be helpful under certain conditions.

A long stream of research on accountability has shown that the effects of accountability differ depending on whether the views of the person to whom one is accountable are known or unknown (Tetlock, 1983). When people are held accountable to someone whose views are known to them, they have the option of behaving in a cognitively "lazy" manner, that is, to simply adopt the person's views without fully exploring all of the potential alternatives (Tetlock, Skitka, \& Boettger, 1989). In contrast, when people are accountable to someone whose views are unknown, they engage in pre-emptive self criticism by considering multiple different perspectives in an attempt to anticipate any potential objections (Tetlock, 1983; Tetlock et al., 1989). This thoughtful approach to decision making is termed integrative complexity (Tetlock, 1983). Applied to creative idea selection, this research suggests that strong faultline groups might benefit from being held accountable to an external evaluator whose preferences are unknown. This point can be illustrated using a concrete example of a brainstorming topic that has been used in past research (Goncalo \& Staw, 2006). In this scenario, a group is asked to generate as many new ideas as possible for a new business that would occupy the space left by a 
mismanaged restaurant. After generating ideas for a specific period of time, they are then asked to select the idea they believe is their most creative. If the group in the above example knows that they will be accountable to someone who thinks that the empty space should be used for another restaurant, they will simply select a restaurant idea from their list. However, if they are accountable to someone whose preferences are unknown, the theory suggests that they will thoroughly explore more ideas in an attempt to select the idea they believe that most people would find highly creative. More importantly, groups that are held accountable to an evaluator whose views are unknown are also more likely to consider multiple different perspectives on an issue in an effort to arrive at a high quality decision and avoid criticism (Lerner \& Tetlock, 1999). The tendency to consider an issue from multiple divergent perspectives might lead strong faultline groups to consider all of the available ideas, even if they were originally suggested by a member of another subgroup.

Proposition 6: Strong faultline groups who are held accountable to an external evaluator with unknown preferences will select more creative ideas than will strong faultline groups who are held accountable to an external evaluator with known preferences. Holding a group accountable for their decision may also attenuate the decision making biases that we proposed would characterize groups with strong faultlines, particularly if they are held accountable not for the final idea they select, but for the process they use to select their best idea. When people are held accountable for decision outcomes, they tend to engage in defensive bolstering of their initial viewpoint, to gather evidence that is biased toward supporting their decision, and to escalate their commitment to their final decision (Simonson \& Staw, 1992). One mechanism that explains this effect is that holding people accountable for important decisions increases stress (Janis \& Mann, 1977) which in turn narrows their attention and perpetuates a 
more simplified decision process (Skitka, Mosier, \& Burdick, 1996). A more effective approach is to hold people accountable for the process they use to arrive at the decision, since decisions that are not arrived at through a sound process are less likely to invite criticism (Simons \& Staw, 1992). Process accountability might benefit strong faultline groups because they would know that if they arrived at their decision through a biased decision making procedure that was driven by in-group favoritism, their decision would be more likely to be overturned, or at least heavily criticized, by external evaluators (Simonson \& Staw, 1992). Thus, we expect that process accountability in groups with strong faultlines should cause each subgroup to more fully consider the ideas and preferences of the other subgroup, thereby representing a logical way to improve selection effectiveness in strong faultline groups.

Proposition 7: Strong faultline groups that are held accountable for the process they used to select their idea will select more creative ideas than strong faultline groups that are held accountable for the idea itself.

In addition to accountability, another approach to improving selection effectiveness might be a social categorization approach in which strong faultline groups are led to form a strong super-ordinate identity that may override the tendency to disregard ideas that were suggested by members of another subgroup (Chatman et al., 1998). The principle of functional antagonism suggests that when one social category becomes salient, other categories such as those derived from demographic differences become less salient (Turner, Oakes, Haslam, \& McGarty, 1994). Diversity in groups triggers ingroup/outgroup distinctions that foster conflict and other problems with social interaction and integration (Williams \& O'Reilly, 1998; Mannix $\&$ Neale, 2005). Conflict is reduced and communication is improved when a super-ordinate identity leads demographically different people to feel similar to each other (Chatman et al., 
1998). The advantages of a super-ordinate identity should be especially salient on convergent tasks such as idea selection which require a great deal of cooperation to reach consensus on a single creative solution.

Although this approach might be beneficial, we also see a number of potential difficulties in applying this strategy successfully. First, it is not clear when a strong super-ordinate identity should be created in strong faultine groups. If a super-ordinate identity is made salient at the idea generation stage, then some worry that the group might deemphasize the unique qualities that make each subgroup unique, thus reducing their ability to generate creative solutions (Swann et al., 2003). A strong faultine group with a strong super-ordinate identity may then more closely resemble a homogeneous group. Second, it might make sense to create a super-ordinate identity just prior to the idea selection stage, but this might prove difficult if sub-group identities are firmly entrenched and difficult to override. Future research might then investigate how super-ordinate identities can be created in strong faultline groups, whether such identities become more difficult to create as the group interacts with each other over an extended period of time, and whether facilitating super-ordinate identification is useful or detrimental for creativity.

\section{Conclusion}

In this paper, we attempted to put forth a number of propositions regarding the relationship between demographic diversity and creativity in groups. We did so by focusing on the influence of faultline strength on creativity, rather than on the relationship between more static measurements of diversity and creativity. We did this because we expect surface-level and deep-level diversity characteristics to interact in influencing the group processes that impact a group's ability to generate many creative ideas and then to select their most creative idea. As is evident in the numerous moderating conditions that we described in this paper, we don't expect 
the relationship between group faultlines and creativity to be a simple one; rather, we expect the relationship to be influenced by a number of contextual factors that organizations must take into account.

In addition to the factors about which we extended formal propositions, we also anticipate that the diversity attributes on which a group's faultlines or subgroup divisions are based may moderate the relationship between faultlines and idea generation and selection. For example, consistent with what is suggested by cognitive resources and social identity theories, we might expect that faultlines based primarily on informational diversity may experience less relationship conflict than groups whose faultlines are based on demographic (social category) diversity. Molleman (2005), for example, found the relationship between faultlines on the one hand and group cohesion and conflict on the other depended on whether the group faultlines were based on ability, personality, or demographic differences. He examined each type of faultline in isolation however, focusing on the relationship between the strength of the faultlines and outcomes; thus future research should, true to faultline theory, examine all such variables simultaneously with the expectation that different diversity structures or patterns created by the interaction of those variables within groups will have implications for creativity processes.

Of course, our propositions have yet to be tested, but we hope that by proposing these ideas, we can help to spark broader discussion about the relationship between diversity and creativity. Furthermore, though we focused on creativity as the outcome of our propositions, future research that differentiates the relationship between diversity and creativity from that involving diversity and innovation (i.e., the implementation of creative ideas), is also needed. We might find, for example, that diversity is more important for creativity than for innovation, and that, in fact, diversity might even slow down implementation processes (e.g., time to market) 
Faultlines and creativity

by stimulating broader discussions of diverse perspectives. Thus, from an organizational perspective, it might be preferable, when possible, to concentrate diversity in creative teams more so than in implementation teams. We encourage researchers to explore such possibilities. 


\section{References}

Abrams, D., Wetherell, M., Cochrane, S., Hogg, M.A. \& Turner, J.C. (1990). Knowing what to think by knowing who you are: Self categorization and the nature of norm formation, conformity and group polarization. British Journal of Social Psychology, 29: 97-119.

Amabile, T. (1983). The social psychology of creativity: A componential conceptualization. Journal of Personality and Social Psychology, 45, 2, 357-376.

Amabile, T. M. Creativity in Context. Boulder, CO: Westview Press, 1996.

Ancona, D. G., \& Caldwell, D. F. (1992). Demography and design: Predictors of new product team performance. Organization Science, 3, 321-341.

Asch, S.E. (1952). Social Psychology. New Jersey: Prentice Hall.

Asch, S.E. (1956). Studies on independence and conformity: A minority of one against a unanimous majority. Psychological Monographs, 70, 9.

Audia, P.G. \& Goncalo, J.A. (2007). Success and creativity over time: A study of inventors in the hard-disk drive industry. Management Science, 53, 1-15.

Moscovici, M. \& Zavalloni, M. (1969). The group as a polarizer of attitudes. Journal of Personality and Social Psychology, 12, 125-135.

Barron F. \& Harrington, D. (1981). Creativity, intelligence, and personality. In M. Rosenzweig \& L. Porter (Eds.), Annual Review of Psychology (Vol.32, pp.439-476). Palo Alto, CA: Annual Reviews.

Beersma, B. \& De Dreu, C.K.W. (2005). Conflict's consequences: Effects of social motives on 
post-negotiation creative and convergent group functioning and performance. Journal of Personality and Social Psychology, 89, 358-374.

Bezrukova, K., \& Jehn, K. A. (2003). The role of group values in the relationship between group faultlines and performance. Paper presented at the 6th annual conference of the International Association for Conflict Management. Melbourne, Australia.

Blalock, H.M. (1967). Toward a theory of minority-group relations. New York: Wiley.

Brewer, M.B. (1991). The social self: On being the same and different at the same time. Personality and Social Psychology Bulletin, 17(5), 475-482.

Brophy, D. R. (1998). Understanding, measuring, and enhancing collective creative problem-solving efforts. Creativity Research Journal, 11, 199-229.

Burnstein, E. \& Vinokur, A. (1973). What a person thinks upon learning he has chosen differently from others: Nice evidence for persuasive arguments explanation of choice shifts. Journal of Experimental Social Psychology, 11, 5: 412-426.

Camacho, L. M., \& Paulus, P. B. (1995). The role of social anxiousness in group brainstorming. Journal of Personality and Social Psychology, 68, 1071-1080.

Chatman, J., Polzer, J., Barsade, S., \& Neale, M. (1998). Being different yet feeling similar: The influence of demographic composition and organizational culture on work processes and outcomes. Administrative Science Quarterly, 43, 749-780.

Chell, E., Haworth, J. \& Brearley, S. (1991). The Entrepreneurial Personality: Concepts, Cases \& Controversies. New York, NY: Routledge. Read Chapter 3: The Search for Entrepreneurial Traits.

Christensen, C.M. (1997). The Innovator's Dilemma: When New Technologies Cause Great Firms to Fail. Boston, MA: Harvard Business School Press. 
Crisp, R. J, \& Hewstone, M. (2001). Multiple categorization and implicit inter-group bias: differential category dominance and the positive-negative asymmetry effect. European Journal of Social Psychology, 31, 45-62.

Crott, H. W., \& Werner, J. (1994). The Norm-Information-Distance-Model: A Stochastic approach to preference change in group interaction. Journal of Experimental Social Psychology, 30 , 68-95

Cox, T., Jr. (1993). Cultural diversity in organizations: Theory, research and practice. San Francisco, CA: Berrett-Koehler Publishers.

Cox, T., Jr., Lobel, S.A., \& McLeod, P.L. (1991). Effects of ethnic groups' cultural differences on cooperative and competitive behavior on a group task. Academy of Management Journal, 34, 827-847.

De Dreu, C.K.W. and West, M.A. (2001). Minority dissent and team innovation: The importance of participation in decision making. Journal of Applied Psychology, 86, 1191-1201.

Deutsch, M. (1973). The resolution of conflict: Constructive and destructive processes. New Haven: Yale University Press.

Diehl, M. \& Stroebe, W. (1987). Productivity loss in brainstorming groups: Toward the solution of a riddle. Journal of Personality and Social Psychology, 53, 1, 497-509.

Earley, P.C., \& Mosakowski, E. (2000). Creating hybrid team cultures: An empirical test of transnational team functioning. Academy of Management Journal, 43(1), 26-49.

Edmondson, A. (1999) Psychological safety and learning behavior in work teams. Administrative Science Quarterly, 44, 350-383.

Eisenhardt, K.M. \& Bougeois, L.J. (1988). Politics of strategic decision making in high-velocity 
environments: Toward a midrange theory. Academy of Management Journal, 31, 4, 737770

Ely, R. J. \& Thomas, D.A. (2001). Cultural diversity at work: The moderating effects of work group perspectives on diversity. Administrative Science Quarterly, 46: 229-273.

Gibson, C. \& Vermeulen, F. (2003). A healthy divide: Subgroups as a stimulus for team learning behavior. Administrative Science Quarterly, 48, 202-239.

Goncalo, J.A. \& Staw, B.M. (2006). Individualism-collectivism and group creativity. Organizational Behavior and Human Decision Processes, 100, 96-109.

Gruenfeld, D.H. (1995). Status, ideology, and integrative complexity on the U.S. Supreme Court: Rethinking the politics of political decision making. Journal of Personality and Social Psychology, 68, 5-20.

Harrison, D.A., Price, K.H. \& Bell, M.P. (1998). Beyond relational demography: Time and the effects of surface and deep level diversity on work group cohesion. Academy of Management Journal, 41, 1, 96-107.

Helson, R. (1996). In search of the creative personality. Creativity Research Journal, 9 , 295-306.

Ilgen, D.R. (1999). Teams imbedded in organizations. American Psychologist, 54 (2), $129-139$.

Ilgen, D., Major, D., Hollenbeck, J. \& Sego, D. (1993). Team research in the 1990's. In M.M. Chemers, \& R. Ayman, (Eds.), Leadership Theory and Research: Perspectives and Direction (pp. 245-270). San Diego, CA: Academic Press.

Janis, I. L. (1971). Groupthink. Psychology Today, 5, 43-44.

Janis, I.L. \& Mann, L. (1977). Decision Making. New York: Free Press 
Jehn, K.A. (1995). A multimethod examination of the benefits and detriments of intragroup conflict. Administrative Science Quarterly, 40, 256-282.

Jehn, K.A., Northcraft, G.B., \& Neale, M.A. (1999). Why differences make a difference: A field study of diversity, conflict, and performance in workgroups. Administrative Science Quarterly, 44, 741-763.

Kasof, J. (1997). Creativity and breadth of attention. Creativity Research Journal, 10: 303-315.

Kiggundu, M.N. (1981). Task interdependence and the theory of job design. Academy of Management Review, 6(3), 499-508.

Li, J. \& Hambrick, D.C. (2005). Factional groups: A new vantage on demographic faultlines, conflict, and disintegration in work teams. Academy of Management Journal, 48(5), 794813.

Lau, D.C., \& Murnighan, K. (1998). Demographic diversity and faultlines: The compositional dynamics of organizational groups. Academy of Management Review, 23(2), 325-340.

Lau, D., \& Murnighan, J. K. (2005). Interactions within groups and subgroups: The effects of demographic faultlines. Academy of Management Journal, 48: 645-659.

Lerner, J. S., \& Tetlock, P. E. (1999). Accounting for the effects of accountability. Psychological Bulletin, 125, 255-275.

Locke, E.A., Tirnauer, D., Roberson, Q., Goldman, B., Latham, M.E., \& Weldon, E. (2001). The importance of the individual in an age of groupism. In M. Turner (Ed.), Groups at Work: Theory and Research (pp. 501-528). Mahway, NJ: Erlbaum. 
Mannix, E. \& Neale, M.A. (2005). What differences make a difference? The promise and reality of diverse teams in organizations. Psychological Science in the Public Interest, 6(2), 3155.

McGrath, J. E. (1984). Groups: Interaction and performance. Englewood Cliffs, NJ: Prentice Hall.

McGrath, J.E. (1997). Small group research, that once and future field: An interpretation of the past with an eye toward the future. Group Dynamics, 1 (1), 7-27. McGrath, J.E. (1984) Groups: Interaction and Performance. New York: Prentice Hall.

McLeod, P.L., Lobel, S.A., \& Cox, T.H., Jr. (1996). Ethnic diversity and creativity in small groups. Small Group Research, 27(2), 248-264.

Milliken, F.J., Bartel, C.A. \& Kurtzberg, T.R. (2003). Diversity and creativity in work groups: A dynamic perspective on the affective and cognitive processes that link diversity and performance. In: Paul Paulus and Bernard Nijstad (Eds.) Group creativity: Innovation through collaboration. New York: Oxford University Press.

Milliken, F.J., \& Martins, L.L. (1996). Searching for common threads: Understanding the multiple effects of diversity in organizational groups. Academy of Management Review, 21(2), 402-433.

Molleman, E. (2005). Diversity in demographic characteristics, abilities and personality traits: Do faultlines affect team functioning? Group Decision and Negotiation, 14, 173-193.

Moscovici S. \& Zavalloni M. (1969). The group as a polarizer of attitudes. Journal of Personality and Social Psychology, 12, 125-135.

Myers, D.G. \& Lamm, H. (1976). Group polarization phenomenon. Psychological Bulletin, 83 (4): $602-627$. 
Nemeth, C.J. (1986). Differential contributions of majority and minority influence. Psychological Review, 93, 23-32.

Nemeth, C., \& Rogers, J. (1996). Dissent and the search for information. British Journal of Social Psychology, 35, 67-76.

Nemeth, C.J. \& Staw B.M. (1989). The tradeoffs of social control and innovation in small groups and organizations. In L. Berkowitz (Ed.) Advances in Experimental Social Psychology: 175-210.

Nijstad, B. A., \& Stroebe, W. (2006). How the group affects the mind: A cognitive model of idea generation in groups. Personality and Social Psychology Review, 10, 186-213.

Osborn, A. F. (1953). Applied Imagination. New York: Charles Scribner's Sons.

Paulus, P.B., Dzindolet, M.T., Poletes, G. \& Camacho, L.M. (1993). Perception of performance in group brainstorming: The illusion of group productivity, Personality and Social Psychology Bulletin 19, 78-89.

Paulus, B. \& Yang, H.C. (2000). Idea generation in groups: A basis for creativity in organizations. Organizational Behavior and Human Decision Processes, 82, 1, 76-87.

Pelled, L. , Eisenhardt, K., and Xin, K. (1999). Exploring the black box: An analysis of work group diversity, conflict and performance, Administrative Science Quarterly, 44(1), 1-28

Perry-Smith, J.E. \& Shalley, C.E. (2003). The social side of creativity: A static and dynamic social network perspective. Academy of Management Review, 29, 89-106.

Phillips, K.W. (2003). The effects of categorically based expectations on minority influence: The importance of congruence. Personality and Social Psychology Bulletin, 29, 1, 3-13.

Phillips, K.Y., Mannix, E.A., Neale, M.A. \& Gruenfeld, D.H. (2004). Diverse groups and 
information sharing: The effects of congruent ties. Journal of Experimental Social Psychology, 40, 497-510.

Phillips, K.W., Northcraft, G., \& Neale, M. (2006). Surface-level diversity and information sharing in groups: When does deep-level similarity help? Group Processes and Intergroup Relations, 9, 4, 467-482.

Polzer, J.T., Milton, L.P., \& Swann, W.B. Jr. (2002). Capitalizing on diversity: Interpersonal congruence in small work groups. Administrative Science Quarterly, 47, 296-324.

Rietzschel, E.F., Nijstad, B.A. \& Stroebe, W. (2006). Productivity is not enough: A comparison of interactive and nominal brainstorming groups on idea generation and selection. Journal of Experimental Social Psychology, 42, 244-251.

Saavedra, R., Earley, P.C., \& Van Dyne, L. (1993). Complex interdependence in taskperforming groups. Journal of Applied Psychology, 78, 1, 61-72.

Sawyer, J.E., Houlette, M.A., \& Yeagley, E.L. (2006). Decision performance and diversity structure: Comparing faultlines in convergent, crosscut, and facially homogeneous groups. Organizational Behavior and Human Decision Processes, 99, 1-15.

Shalley, C.E. \& Gilson, L.L. (2004). What leaders need to know: A review of social and contextual factors that can foster or hinder creativity. Leadership Quarterly, 15: 33-53.

Shaw, J.B. (2004). The development and analysis of a measure of group faultlines. Organizational Research Methods, 7 (1): 66-100.

Simonson, I., \& Staw, B. M. (1992). De-escalation strategies: A comparison of techniques for reducing commitment to losing courses of action. Journal of Applied Psychology, 77, 419-426. 
Skitka, L. J., Mosier, K., \& Burdick, M. D. (1996). Accountability and automation bias. In J. S. Lemer \& P. E. Tetlock (Chairs), Accountability: The social context of cognition. Symposium conducted at the $8^{\text {th }}$ Annual Convention of the American Psychological Society, San Francisco, CA.

Stasser, G. \& Stewart, D. (1992). Discovery of hidden profiles by decision making groups: Solving a problem versus making a judgment. Journal of Personality and Social Psychology, 57, 67-78.

Stoner, J. A. F. (1961). A comparison of individual and group decisions involving risk. Unpublished Master's Thesis, Massachusetts Institute of Technology.

Stroebe, W., Diehl, M., \& Abakoumkin, G. (1992). The illusion of group effectivity. Personality and Social Psychology Bulletin, 18, 643-650

Subramaniam, M. \& Youndt, M.A., 2005. The influence of intellectual capital on the nature of innovative capabilities. Academy of Management Journal, 48(3), 450-464.

Swann, W.B. Jr., Kwan, V.S.Y., Polzer, J.T., \& Milton, L.P. (2003). Fostering group identification and creativity in diverse groups: The role of individuation and selfverification. Personality and Social Psychology Bulletin, 29(11), 1396-1406.

Swann, W.B. Jr., Milton, L.P., \& Polzer, J.T. (2000). Should we create a niche or fall in line? Identity negotiation and small group effectiveness. Journal of Personality and Social Psychology,79, 2, 238-250.

Taylor DM, Doria JR. 1981. Self-serving and group-serving bias in attribution. Journal of Social Psychology, 113, 201- 211.

Tetlock, P. E. (1983). Accountability and complexity of thought. Journal of Personality and Social Psychology, 45, 74-83. 
Tetlock, P. E. (1992). The impact of accountability on judgment and choice: Toward a social contingency model. Advances in Experimental Social Psychology, 25, 331-376.

Tetlock, P. E., Skitka, L., \& Boettger, R. (1989). Social and cognitive strategies for coping with accountability: Conformity, complexity, and bolstering. Journal of Personality and Social Psychology, 57, 632-640.

Thatcher, S.M.B., Jehn, K.A., \& Zanutto, E. (2003). Cracks in diversity research: The effects of diversity faultlines on conflict and performance. Group Decision and Negotiation, 12(3), 217-241.

Tolbert, P., Andrews, A., \& Simons, T. (1995). The effects of group proportions on group dynamics. In S. Jackson \& M. Ruderman (Eds.), Diversity in workteams (pp. 131-159). Washington, DC: APA Books.

Turner, J.C., Oakes, P.J., Haslam, A., \& McGarty, C. (1994). Self and collective: Cognition and social context. Personality and Social Psychology Bulletin, 20, 454-463.

Van Ginkel, W., \& Van Knippenberg, D. (2003). The role of shared mental models for informational diversity in group decision making. Paper presented at the European Association of Experimental Social Psychology Small Group Meeting on Small Group Decision Making, Amsterdam.

Van Knippenberg, D., De Dreu, C.K.W., \& Homan, A.C. (2004). Work group diversity and group performance: An integrative model and research agenda. Journal of Applied Psychology, 89, 6, 1008-1022.

Wageman, R. (1995). Interdependence and group effectiveness. Administrative Science Quarterly, 40, 145-180.

Williams, K., \& O'Reilly, C. (1998). Demography and diversity in organizations: A 
Faultlines and creativity

review of 40 years of research. In B. M. Staw \& L. L. Dummings (Eds.), Research in Organizational Behavior, Vol. 20, (pp. 77-140). Greenwich, CT: JAI Press. 